\title{
Role of aflibercept for macular edema following branch retinal vein occlusion: comparison of clinical trials
}

This article was published in the following Dove Press journal:

Clinical Ophthalmology

8 March 2016

Number of times this article has been viewed

\author{
Patrick Oellers ${ }^{1,2}$ \\ Dilraj S Grewal ${ }^{1,2}$ \\ Sharon Fekrat ${ }^{1,2}$ \\ 'Duke Eye Center, Duke University \\ Medical Center, ${ }^{2}$ Surgical Service, \\ Durham Veterans Affairs Medical \\ Center, Durham, NC, USA
}

\begin{abstract}
For years, the standard of care for branch-retinal-vein-occlusion-associated macular edema was initial observation followed by grid-pattern laser photocoagulation for persistent edema. Newer pharmacologic options have revolutionized the management of branch-retinal-vein-occlusionassociated macular edema, and the visual outcomes of these eyes are better than ever. However, a variety of available treatment options including intravitreal corticosteroids and intravitreal antivascular endothelial growth factor agents have established novel challenges with regard to appropriate drug selection. This review summarizes the available clinical studies with special emphasis on the comparison of intravitreal aflibercept with ranibizumab, bevacizumab, and steroid agents.

Keywords: branch retinal vein occlusion, BRVO, macular edema, cystoid macular edema, grid-pattern laser photocoagulation, triamcinolone, dexamethasone implant, ranibizumab, bevacizumab, pegaptanib, anti-vascular endothelial growth factor
\end{abstract}

\section{Introduction}

Branch retinal vein occlusion (BRVO) is a common retinal vascular disease with an estimated incidence of 13.9 million per year worldwide and 150,000 per year in the USA. ${ }^{1-3}$ Vision-threatening sequelae include macular edema (ME), retinal ischemia, neovascularization of the disk and elsewhere, vitreous hemorrhage, and less commonly, neovascular glaucoma. ${ }^{4}$ For many decades, the treatment for BRVO has been directed by the pivotal Branch Vein Occlusion Study (BVOS), which suggested grid-pattern laser photocoagulation for angiographically perfused ME as the standard of care for select eyes that do not exhibit spontaneous resolution of ME within 3 months of onset. ${ }^{5}$ However, in recent years, there has been significant advancement in the pharmacotherapy for ME associated with BRVO. Intravitreal corticosteroids can lead to the temporary resolution of edema in many cases, but their use has been tempered by steroid-related glaucoma and cataract formation and progression. ${ }^{6} \mathrm{~A}$ long-term-release intravitreal dexamethasone implant has been approved by the US Food and Drug Administration (FDA) with the known glaucoma and cataract risks. ${ }^{7}$ Inhibitors of vascular endothelial growth factor (VEGF) have revolutionized the treatment of ME associated with BRVO, a condition that is sensitive to VEGF. There are four different anti-VEGF medications available for intravitreal administration: pegaptanib, ${ }^{8}$ bevacizumab, ${ }^{9}$ ranibizumab, ${ }^{10}$ and more recently, aflibercept. ${ }^{11}$ Amidst increased treatment choices and improved outcomes for retinal venous occlusive disease, the retina community faces new challenges to determine the optimum drug and associated dosing frequency. This review outlines recent trials evaluating treatment
Correspondence: Sharon Fekrat

Duke Eye Center, Duke University Medical Center 3802, 235I Erwin Road,

Durham, NC 27710, USA

Tel +19196841857

Fax +19196816474

Email fekra00I@mc.duke.edu (c) (1) (5) 2016 0ellers et al. This work is published and licensed by Dove Medical Press Limited. The full terms of this license are available at https://www.dovepress.com/terms.php (c) ${ }_{\mathrm{BY}} \mathrm{NC}$ and incorporate the Creative Commons Attribution - Non Commercial (unported, v3.0) License (http://creativecommons.org/licenses/by-nc/3.0/). By accessing the work you hereby accept the Terms. Non-commercial uses of the work are permitted without any further permission from Dove Medical Press Limited, provided the work is properly attributed. For permission for commercial use of this work, please see paragraphs 4.2 and 5 of our Terms (https://www.dovepress.com/terms.php). 
options for BRVO-associated ME, with special emphasis on aflibercept, to highlight the complexities and challenges of the management of eyes with ME due to BRVO.

\section{Laser photocoagulation}

Almost 30 years ago, the BVOS demonstrated that eyes with perfused ME on fluorescein angiography benefited from gridpattern argon laser photocoagulation. ${ }^{5}$ Patients with visual acuity $<20 / 40$ were randomized to either laser photocoagulation or observation. Sixty-four percent of treated eyes gained two or more lines of vision compared with $34 \%$ in the observation arm at 3 years. Although the study was not designed to evaluate the optimal timing of treatment, results also showed that treatment within $<12$ months of the occlusive event fared better compared with treatment initiated $>12$ months $(78 \%$ gain $\geq 2$ lines versus $53 \%$, respectively). Taking into account that one-third of eyes improved over time and the possible detrimental effects of laser, the standard of care had been to wait for spontaneous vision improvement for 3 months, and if not improved apply grid-pattern laser photocoagulation for those eyes with persistent perfused ME.

\section{Pharmacotherapy}

Pharmacologic therapy with intravitreal medications has substantially changed the management of BRVO-associated $\mathrm{ME}$ as described in the following sections. Select clinical trials are outlined in Table 1.

\section{Intravitreal corticosteroids}

Several studies have shown positive effects of intravitreal corticosteroids, likely due to their anti-inflammatory and specifically VEGF-inhibiting effects. ${ }^{12-17}$

The Standard care versus COrticosteroid for REtinal vein occlusion trial (SCORE) evaluated intravitreal triamcinolone in a randomized, multicenter fashion. Participants with BRVO or hemiretinal vein occlusion with best-corrected visual acuity (BCVA) between 20/40 and 20/400 were randomized into either $1 \mathrm{mg}$ or $4 \mathrm{mg}$ of intravitreal triamcinolone or standard-of-care treatment, consisting of gridpattern laser photocoagulation. ${ }^{6}$ After 12 months, there were no significant differences in visual outcome between the groups (rates of two line gainers were 29\%, 26\%, and 27\% in the standard of care and $1 \mathrm{mg}$ and $4 \mathrm{mg}$ triamcinolone groups, respectively), whereas adverse events, including intraocular pressure (IOP) elevation $(7 \%, 41 \%$, and $1 \%$ required IOP-lowering medication in the $1 \mathrm{mg}$ triamcinolone, $4 \mathrm{mg}$ triamcinolone, and standard-of-care groups, respectively) and cataract progression (25\% and $35 \%$ in the $1 \mathrm{mg}$ and $4 \mathrm{mg}$ triamcinolone groups versus $13 \%$ in the standard-of-care group) were significantly more common in the $4 \mathrm{mg}$ triamcinolone group. Subgroup analysis of pseudophakic eyes did not demonstrate a significant beneficial effect on visual acuity when compared with that of phakic eyes treated similarly; thus, cataract progression in the treated groups did not adversely affect visual outcome at 12 months. Optical coherence tomography (OCT)-assessed reduction in center-point thickness was similar between the three groups. Of note, one case of endophthalmitis occurred in the $1 \mathrm{mg}$ triamcinolone group. The authors concluded that, given equivalent functional outcomes, but different safety profiles, grid-pattern laser photocoagulation should remain the standard treatment for eyes with perfused ME as well as the benchmark for future clinical trials.

The multicenter, sham-controlled randomized trial of Dexamethasone Intravitreal Implant in Patients with ME due to Retinal Vein Occlusion (GENEVA) evaluated an intravitreal sustained-release dexamethasone implant delivered via a 22 gauge needle (Ozurdex; Allergan, Inc., Irvine, CA, USA) for patients with visual acuity between 20/50 and 20/200 and central subfield thickness (CFT) $\geq 300 \mu \mathrm{m}$ due to BRVO or central retinal vein occlusion (CRVO). ${ }^{7}$ Groups were randomized into $0.35 \mathrm{mg}$ dexamethasone, $0.7 \mathrm{mg}$ dexamethasone, or sham injection. Subgroup analysis was performed separately for BRVO and CRVO. For BRVO (as well as for CRVO), after 6 months, there was no significant difference in the percentage of 15 -letter gainers between the groups $(21 \%, 23 \%$, and $20 \%$ in the $0.35 \mathrm{mg}$ dexamethasone, $0.7 \mathrm{mg}$ dexamethasone, and sham groups, respectively). However, vision at 2 months for both treatment doses was statistically significantly better compared with sham $(26 \%$, $30 \%$ for the $0.35 \mathrm{mg}$ and $0.7 \mathrm{mg}$ dexamethasone groups versus $13 \% 15$-letter gainers), implying a steroid effect on the initial speed of visual recovery. Ocular hypertension was only evaluated in a pooled analysis of CRVO and BRVO. It occurred in $4 \%$ in the dexamethasone groups versus $0.7 \%$ in the sham group, and this difference was significant. Most patients with increased IOP were managed medically, but five patients in the dexamethasone group required an IOP-reducing procedure. Cataract was reported in $4.1 \%$ in the $0.35 \mathrm{mg}$ dexamethasone group, $7.3 \%$ in the $0.7 \mathrm{mg}$ dexamethasone group versus $1.0 \%$ in the sham group and was not statistically different among the groups. The authors concluded that dexamethasone implants hasten the visual recovery in eyes with BRVO and thus may be a useful therapeutic option. GENEVA was followed by a 6-month, open-label extension study of the $0.7 \mathrm{mg}$ dexamethasone implant, which 


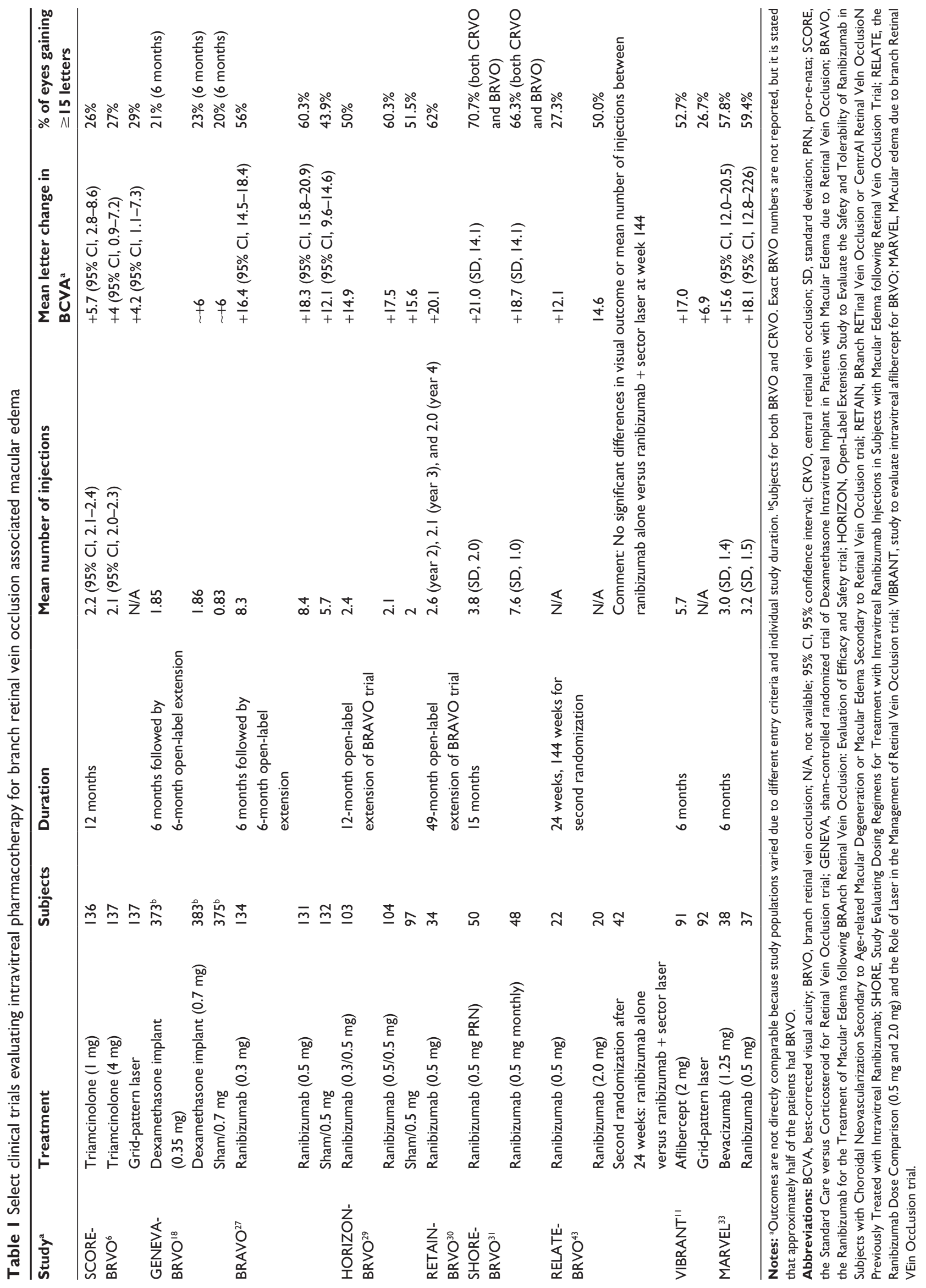


yielded similar results. ${ }^{18}$ Based on this trial, $0.7 \mathrm{mg}$ Ozurdex was the first intravitreal agent to receive FDA approval for BRVO-associated ME.

\section{Intravitreal anti-VEGF agents}

Several lines of evidence suggest that VEGF is a major mediator for ME in BRVO. ${ }^{19-23}$ Ischemic retinas express VEGF, and the severity of vein occlusion correlates with VEGF concentration in the vitreous fluid. VEGF vitreous concentration in eyes with CRVO is measured higher than BRVO. ${ }^{19,24,25}$ Numerous studies have demonstrated the resolution of $\mathrm{ME}$ and improvement of vision in response to pharmacologic VEGF inhibition. ${ }^{26}$

\section{Ranibizumab}

Ranibizumab (Lucentis; Genentech, Inc., South San Francisco, CA, USA) is a humanized monoclonal antibody fragment (Fab) that binds VEGF. The ranibizumab for the treatment of macular edema following BRAnch Retinal Vein Occlusion: Evaluation of Efficacy and Safety (BRAVO) trial evaluated the use of ranibizumab versus sham injection for BRVO-associated ME. ${ }^{10}$ BRAVO included eyes diagnosed with BRVO within 12 months of study entry and a BCVA between 20/40 and 20/400 with CFT $\geq 250 \mu \mathrm{m}$ as assessed by OCT. A notable exclusion criterion was the presence of a brisk relative afferent pupillary defect. Three study arms were included: monthly $0.3 \mathrm{mg}$ or $0.5 \mathrm{mg}$ intravitreal ranibizumab versus sham injection. Grid-pattern laser photocoagulation was permitted as rescue therapy in all groups at 3 months. At 6 months, visual improvement was significantly greater for both ranibizumab groups than sham. Mean Early Treatment Diabetic Retinopathy Study letter score improvement was 16.6 and 18.3 in the $0.3 \mathrm{mg}$ and $0.5 \mathrm{mg}$ ranibizumab groups, respectively, and 7.3 in the sham group. The percentage of 15-letter gainers was $55.2 \%(0.3 \mathrm{mg}), 61.1 \%(0.5 \mathrm{mg})$ for ranibizumab eyes versus $28.8 \%$ in sham eyes. CFT decreased by a mean of $337 \mu \mathrm{m}(0.3 \mathrm{mg})$ and $345 \mu \mathrm{m}(0.5 \mathrm{mg})$ in the ranibizumab groups, which was greater than the $158 \mu \mathrm{m}$ reduction in the sham group. More patients in the sham group (54.5\%) received rescue grid-pattern laser compared with those in the $0.3 \mathrm{mg}(18.7 \%)$ and $0.5 \mathrm{mg}(19.8 \%)$ ranibizumab groups. Following the initial 6-month study period, all groups, including the sham group, were treated with ranibizumab on a pro-re-nata (PRN) basis if BCVA was $\leq 20 / 40$ or CFT $\geq 250 \mu \mathrm{m} .{ }^{27}$ The sham group received $0.5 \mathrm{mg}$ ranibizumab; the $0.5 \mathrm{mg}$ and $0.3 \mathrm{mg}$ groups remained on their previously assigned dose. The proportion of eyes that gained $\geq 15$ letters from the baseline BCVA at month 12 was $56.0 \%(0.3 \mathrm{mg})$, $60.3 \%$ (0.5 mg), and 43.9\% (sham/0.5 mg).
Overall, adverse events were not common in BRAVO. Intraocular adverse events included one retinal detachment and one case of endophthalmitis in the ranibizumab group. Systemic adverse events included one fatal cerebral hemorrhage and one nonfatal myocardial infarction also in the ranibizumab group. ${ }^{27} \mathrm{~A}$ retrospective analysis of BRAVO patients evaluated the evolution of angiographic retinal non-perfusion. The percentage of eyes without retinal nonperfusion at month 6 was significantly greater in the $0.3 \mathrm{mg}$ (48.1\%) and $0.5 \mathrm{mg}(51.0 \%)$ ranibizumab groups compared with sham $(32.7 \%){ }^{28}$

A subset of patients enrolled in BRAVO was followed in two open-label, single-arm extension studies evaluating long-term outcomes. The first was a 12-month, Open-Label Extension Study to Evaluate the Safety and Tolerability of Ranibizumab in Subjects with Choroidal Neovascularization Secondary to Age-related Macular Degeneration or Macular Edema Secondary to Retinal Vein Occlusion (HORIZON). ${ }^{29}$ Here, all groups received $0.5 \mathrm{mg}$ ranibizumab on a PRN basis every 3 months, and visual acuity gains were maintained. A subset of patients enrolled in BRAVO and HORIZON was then further followed for 2 years in the BRanch RETinal Vein Occlusion or CentrAl Retinal VeIn OcclusioN Previously Treated with Intravitreal Ranibizumab (RETAIN) study (a total of 4-year follow-up). ${ }^{30}$ Patients were observed every 3 months and were eligible for an intravitreal ranibizumab injection if there was intraretinal fluid involving the fovea as evaluated by OCT (PRN regimen). Generally, beneficial results with regard to visual acuity and macular thickness were sustained after 4 years of enrollment in the BRAVO trial, with a mean number of injections per year of 2 . At the end of the RETAIN trial, $50 \%$ of eyes had resolved ME (defined as the absence of intraretinal fluid for 6 months without injection) and $80 \%$ of these patients had a BCVA $\geq 20 / 40$, whereas the other $50 \%$ still required an average of three injections per year with BCVA $\geq 20 / 40$ in $80 \%$. The authors concluded that ranibizumab administration resulted in excellent outcomes for BRVO patients, and although half of them still required injections at 4 years, they maintained good visual acuity.

A randomized multicenter trial named Study Evaluating Dosing Regimens for Treatment with Intravitreal Ranibizumab Injections in Subjects with Macular Edema following Retinal Vein Occlusion (SHORE) demonstrated no significant difference between monthly versus monthly PRN ranibizumab dosing in patients with resolved ME after seven initial monthly ranibizumab injections. ${ }^{31}$ To our knowledge, no controlled trials have evaluated a treat-and-extend regimen in BRVO. 


\section{Aflibercept}

Aflibercept (Eylea; Regeneron, Tarrytown, NY, USA) is a recombinant fusion protein consisting of VEGFbinding receptors 1 and 2 fused to the $\mathrm{Fc}$ portion of human immunoglobulin G. In 2015, a multicenter, randomized trial, named VIBRANT, evaluated intravitreal aflibercept for BRVO-associated ME. ${ }^{11}$ Unlike BRAVO, which compared anti-VEGF treatment with sham, this study directly compared aflibercept treatment with grid-pattern laser photocoagulation. A total of 183 eyes with $\mathrm{BRVO}$ or hemiretinal vein occlusion and BCVA between 20/40 and 20/320 were randomized into either $2 \mathrm{mg}$ monthly intravitreal aflibercept injections with sham grid-pattern laser at baseline or gridpattern laser. Interestingly, laser was instituted at baseline, instead of after 3 months of observation as in BVOS or BRAVO rescue. Both groups were eligible to receive laser as rescue therapy at certain time points; however, the laser group was not eligible for anti-VEGF rescue treatment. At week $24,52.7 \%$ of eyes gained 15 or more letters in the aflibercept group versus $26.7 \%$ in the laser group. Mean Early Treatment Diabetic Retinopathy Study letter improvement score was 17.0 in the aflibercept versus 6.9 in the laser group at 24 weeks. Mean reduction in central retinal thickness was $280.5 \mu \mathrm{m}$ in the aflibercept versus $128 \mu \mathrm{m}$ in the laser group. The study found a significantly higher proportion of eyes with perfused retina at 6 months in the aflibercept group compared with the laser group, whereas both groups had a comparable baseline perfusion status. In terms of serious adverse events, three eyes in the laser group developed retinal neovascularization, but none did in the aflibercept group. One traumatic cataract occurred in the aflibercept group, and one case of nonfatal stroke and one case of fatal pneumonia occurred in the laser group. No systemic vascular adverse events were reported in the aflibercept group. The study concluded that intravitreal aflibercept is an effective treatment for BRVOassociated ME. Contrary to BRAVO, which continued to treat patients on a PRN basis after 6 months, VIBRANT will follow and treat patients every 8 weeks going forward until month 12. The results of this follow-up study have not yet been published at the time of this review.

\section{Bevacizumab}

Bevacizumab (Avastin; Genentech, Inc.) is a monoclonal humanized full-length antibody binding to VEGF. Developed for non-ocular use by Genentech, Inc., the company that also holds the rights to ranibizumab, no industrysponsored ophthalmology trials were conducted. However, much of our knowledge about VEGF inhibition in the eye is derived from the numerous studies and anecdotal reports with regard to bevacizumab - driven by the many clinicians poised to use this drug due to its pharmacological similarities yet economical advantages when compared with ranibizumab.

A small trial evaluating bevacizumab treat-and-extend in BRVO has shown favorable results. ${ }^{32}$ A randomized, singlecenter, masked trial named MAcular edema due to branch Retinal VEin OccLusion (MARVEL) was conducted to directly compare bevacizumab with ranibizumab for BRVOassociated ME. ${ }^{33}$ In this study, intravitreal injections were administered on a PRN basis. After 6 months, both groups had comparable BCVA and central retinal thickness. The mean number of injections was 3.2 for ranibizumab and 3.0 for bevacizumab. However, MARVEL failed to demonstrate non-inferiority of bevacizumab based on a 5-letter mean visual acuity difference. The mean difference was only 2.5 letters between the groups at 6 months, the $95 \%$ confidence interval ranged from -8 to +5 letters. Given the results of the study, it remains unclear whether non-inferiority for functional outcomes, which were established for bevacizumab against ranibizumab for age-related macular degeneration in the Comparison of Age-related macular degeneration Treatment Trials (CATT) study, ${ }^{34}$ might also apply to eyes with BRVO. In addition, despite its structural similarities to ranibizumab, bevacizumab's systemic safety has been questioned in persons with retinal venous occlusion who may be more prone to systemic vascular events. To this note, protocol $\mathrm{T}$ by the DRCR.net, which was a head-to-head study between bevacizumab, ranibizumab, and aflibercept for diabetic ME, did not demonstrate increased systemic adverse events for either of the drugs ${ }^{35}$ nor did the CATT study undermine these concerns. ${ }^{34}$ However, despite its widespread national and international use for an array of retinal conditions, bevacizumab remains off-label use.

\section{Pegabtinib}

Pegabtinib (Macugen; Bausch \& Lomb Incorporated, Bridgewater, NJ, USA) is an aptamer (single strand of nucleic acid) that specifically binds to one VEGF isoform, VEGF-165, and had been evaluated in a small dose-finding study without sham control for BRVO in 2009. ${ }^{36}$ Likely not as effective as its anti-VEGF competitors, the drug has not been further studied in BRVO and is not FDA approved for BRVO.

\section{Do the data from clinical trials help guide drug selection and frequency of administration?}

There is no doubt that the advent of anti-VEGF intravitreal pharmacotherapy has revolutionized the management of 
eyes with ME due to BRVO. Given the impressive results of ranibizumab and aflibercept in the BRAVO and VIBRANT trials, anti-VEGF drugs have become the gold standard for the treatment of BRVO-associated ME. Compared with available natural history studies and data from the sham treatment arms of the aforementioned trials that consistently demonstrated visual acuity gains in about one-third of patients, these antiVEGF studies demonstrate robust visual acuity gains and anatomical improvement in the vast majority of eyes. With these groundbreaking results in mind, several questions remain to be tackled to further improve and refine patient care in clinical practice:

1. Which anti-VEGF drug to choose?

2. What is the best treatment frequency regimen?

3. Is there a role for combination treatment of anti-VEGF with steroids or laser?

Can we get answers to these questions from the available clinical trials?

Which anti-VEGF drug to choose? It may be tempting to compare trial results of BRAVO and VIBRANT to find whether ranibizumab or aflibercept is superior, since both trials have tested anti-VEGF drugs for the same disease. In BRAVO, $61 \%$ of subjects gained $\geq 15$ letters $(0.5 \mathrm{mg}$ group) compared with $52 \%$ in VIBRANT. Mean letter gains were 18 in BRAVO versus 17 in VIBRANT. ${ }^{10,11}$ A recent meta-analysis concluded equivalent efficacy of both drugs based on the available studies. ${ }^{37}$ However, in our opinion, nonequivalent endpoints (BRAVO's primary endpoint was the mean change in BCVA, whereas VIBRANT's primary endpoint was the proportion of eyes improving 15 or more letters) as well as different inclusion and exclusion criteria make this comparison challenging. It is however notable that VIBRANT was neither designed as a non-inferiority trial against ranibizumab nor allowed ranibizumab rescue therapy, although at the time of recruitment ranibizumab was FDA approved and clearly superior to laser. This should prompt the ophthalmology community to strive for increased uniformity for clinical trials among inclusion and exclusion criteria when studying similar disease entities and to select the same primary endpoints and control groups. ${ }^{38,39}$ In this regard, no direct head-to-head studies of ranibizumab and aflibercept have been undertaken in BRVO at this time. Since bevacizumab is not FDA approved for intravitreal use, its usage remains off-label. Nevertheless, its effectiveness is evident with a decade of clinical use, and it clearly offers economical advantages. However, the MARVEL study failed to demonstrate non-inferiority of bevacizumab to ranibizumab, although this could have been due to the inadequate power of the study. Interestingly, bevacizumab is the preferred treatment option by $61 \%$ of the US retina specialists followed by aflibercept (17\%) and ranibizumab (17\%), indicating that economical considerations contribute a major part toward decision making in clinical practice as revealed by the American Society of Retina Specialists 2015 membership Preferences and Trends survey. ${ }^{40}$ At this time, however, available evidence does not allow conclusions on comparative effectiveness of the different anti-VEGF drugs.

\section{What is the best treatment frequency regimen to administer anti-VEGF drugs?}

From the HORIZON and SHORE studies, we know that a monthly PRN regimen can have equivalent visual and anatomical outcomes in patients who were previously treated with monthly injections. However, both a monthly fixed regimen and a monthly $\mathrm{PRN}$ regimen are associated with significant health care burden. Concerns were voiced recently that frequent anti-VEGF injections may result in progression of geographic atrophy in age-related macular degeneration. ${ }^{41}$ In clinical practice, there is considerable interest in the treatand-extend approach. However, currently, little information about treat-and-extend regimens for BRVO exists in the literature. One anecdotal noncontrolled study suggests that treat-and-extend may be a reasonable regimen with the advantage of reducing the number of office visits, number of injections, and associated costs. ${ }^{32}$ The 2015 American Society of Retina Specialists member Preferences and Trends survey reveals that treat-and-extend is the most common approach $(56 \%)$ by the US retina specialists followed by monthly treatment until dry and subsequent monthly PRN (40\%) for retinal vein occlusion associated with decreased vision. ${ }^{40}$

It is interesting that while the majority of eyes with BRVO-associated ME have excellent visual results with anti-VEGF treatment, long-term follow-up data from the RETAIN study demonstrated that even after 4 years, 50\% of eyes still require ranibizumab injections for $\mathrm{ME} .{ }^{30}$ Hence, it is reasonable to question whether there may be a role for combination treatment with laser or steroid medication in addition to anti-VEGF agents to possibly reduce treatment burden. A randomized controlled trial demonstrated the superiority of intravitreal ranibizumab when compared with grid-pattern laser for eyes with BRVO. ${ }^{42}$ However, both BRAVO and VIBRANT allowed rescue laser treatment in their respective anti-VEGF groups. In BRAVO, rescue laser was performed in $19 \%(0.3 \mathrm{mg})$ and $20 \%(0.5 \mathrm{mg})$ in the ranibizumab groups, 
whereas no aflibercept-treated eyes received rescue laser during the first 6 months of the VIBRANT trial. No studies to our knowledge have evaluated anti-VEGF medication alone versus anti-VEGF medication plus grid-pattern-laser photocoagulation. However, the percentage of patients who were enrolled in the RETAIN study and received grid laser photocoagulation with resolved versus unresolved edema was $60 \%$ and $63 \%$, respectively, and they did not differ significantly in visual outcome, anatomic outcome, or number of needed injections. ${ }^{30}$ It is unclear whether eyes receiving grid laser actually benefited from it, since laser therapy was not controlled between eyes that received it and those that did not. In addition to grid laser photocoagulation, peripheral scatter laser photocoagulation has drawn interest to possibly reduce the anti-VEGF load. However, a recent study did not show reduced anti-VEGF treatment burden secondary to scatter laser photocoagulation to non-perfused areas identified by a wide-angle fluorescein angiography in eyes treated with intravitreal ranibizumab given on a monthly PRN basis. ${ }^{43}$ It may be that scatter laser photocoagulation would offer benefit by reducing VEGF load for more ischemic-type BRVO eyes with recalcitrant edema despite frequent anti-VEGF injections, but this requires further study. In addition, the role of steroids in the modern management of BRVO is not entirely clear. The two prospective trials evaluating steroids - SCORE and GENEVA - demonstrated similar visual outcomes in the treatment groups compared with their respective control groups. Interestingly, the GENEVA study demonstrated a faster speed of visual recovery in long-term-release dexamethasone implant eyes compared with sham. To our knowledge, no clinical trials have evaluated the effect of combination therapy with intravitreal triamcinolone or long-term-release dexamethasone and anti-VEGF medication. In conclusion, the role of laser therapy or steroid administration in addition to anti-VEGF is not clear and requires further study. However, it may be reasonable to offer this approach to patients who have recalcitrant edema despite frequent anti-VEGF injections.

\section{Conclusion}

In summary, we are fortunate to have an array of therapeutic options available for our patients with BRVO. The quantity of treatment choices will likely grow even more over the next few years, with different therapeutic solutions including extended-release anti-VEGF technology, gene vector transfer, and stem cells on the not-so-distant horizon. Anti-VEGF drugs have revolutionized the management of BRVO-associated ME. At this time, both ranibizumab and aflibercept are effective treatment options; bevacizumab usage for BRVO remains off-label, but its safety and efficacy have been extensively validated both anecdotally and in a head-to-head trial - thus we must note that non-inferiority has not been established against ranibizumab in BRVO. The combination of anti-VEGF drugs with steroids or laser may be a reasonable option for eyes with recalcitrant edema despite frequent anti-VEGF injections, but further study is needed on how to best manage these patients. Better harmonization and definition of the control group in clinical studies may allow for more sophisticated comparisons at least for the same class of drugs. At this time, the available data do not allow for an evidence-based answer to the question about the best treatment option in general, or for an individual patient, and we continue to rely to some extent on our personal bias and possibly the medico-economical environment.

\section{Disclosure}

The authors have not received any financial support for this article and report no conflicts of interest in this work.

\section{References}

1. Klein R, Klein BE, Moss SE, Meuer SM. The epidemiology of retinal vein occlusion: the Beaver Dam Eye Study. Trans Am Ophthalmol Soc. 2000;98:133-141. discussion 41-3.

2. Rogers S, McIntosh RL, Cheung N, et al; International Eye Disease Consortium. The prevalence of retinal vein occlusion: pooled data from population studies from the United States, Europe, Asia, and Australia. Ophthalmology. 2010;117:313.e1-319.e1.

3. Klein R, Moss SE, Meuer SM, Klein BE. The 15-year cumulative incidence of retinal vein occlusion: the Beaver Dam Eye Study. Arch Ophthalmol. 2008;126:513-518.

4. Rogers SL, McIntosh RL, Lim L, et al. Natural history of branch retinal vein occlusion: an evidence-based systematic review. Ophthalmology. 2010;117:1094.e5-1101.e5.

5. Argon laser photocoagulation for macular edema in branch vein occlusion. The Branch Vein Occlusion Study Group. Am J Ophthalmol. 1984; 98:271-282.

6. Scott IU, Ip MS, VanVeldhuisen PC, et al; SCORE Study Research Group. A randomized trial comparing the efficacy and safety of intravitreal triamcinolone with standard care to treat vision loss associated with macular Edema secondary to branch retinal vein occlusion: the Standard Care vs Corticosteroid for Retinal Vein Occlusion (SCORE) study report 6. Arch Ophthalmol. 2009;127:1115-1128.

7. Haller JA, Bandello F, Belfort R Jr, et al; OZURDEX GENEVA Study Group. Randomized, sham-controlled trial of dexamethasone intravitreal implant in patients with macular edema due to retinal vein occlusion. Ophthalmology. 2010;117:1134.e3-1146.e3.

8. Wroblewski JJ, Wells JA 3rd, Adamis AP, et al; Central Retinal Vein Occlusion Study Group. Pegaptanib sodium for macular edema secondary to central retinal vein occlusion. Arch Ophthalmol. 2009;127:374-380.

9. Ehlers JP, Decroos FC, Fekrat S. Intravitreal bevacizumab for macular edema secondary to branch retinal vein occlusion. Retina. 2011;31: 1856-1862.

10. Campochiaro PA, Heier JS, Feiner L, et al; BRAVO Investigators. Ranibizumab for macular edema following branch retinal vein occlusion: six-month primary end point results of a phase III study. Ophthalmology. 2010;117:1102.e1-1112.e1. 
11. Campochiaro PA, Clark WL, Boyer DS, et al. Intravitreal aflibercept for macular edema following branch retinal vein occlusion: the 24-week results of the VIBRANT study. Ophthalmology. 2015;122:538-544.

12. Bearelly S, Cooney MJ, Stinnett S, Fekrat S. Intravitreal triamcinolone for cystoid macular edema related to branch retinal vein occlusion. Ann Ophthalmol (Skokie). 2006;38:317-320.

13. Chen SD, Lochhead J, Patel CK, Frith P. Intravitreal triamcinolone acetonide for ischaemic macular oedema caused by branch retinal vein occlusion. Br J Ophthalmol. 2004;88:154-155.

14. Chen SD, Sundaram V, Lochhead J, Patel CK. Intravitreal triamcinolone for the treatment of ischemic macular edema associated with branch retinal vein occlusion. Am J Ophthalmol. 2006;141:876-883.

15. Jonas JB, Akkoyun I, Kamppeter B, Kreissig I, Degenring RF. Branch retinal vein occlusion treated by intravitreal triamcinolone acetonide. Eye (Lond). 2005;19:65-71.

16. Jonas JB, Kreissig I, Degenring RF. Intravitreal triamcinolone acetonide as treatment of macular edema in central retinal vein occlusion. Graefes Arch Clin Exp Ophthalmol. 2002;240:782-783.

17. Nauck M, Karakiulakis G, Perruchoud AP, Papakonstantinou E, Roth M. Corticosteroids inhibit the expression of the vascular endothelial growth factor gene in human vascular smooth muscle cells. Eur J Pharmacol. 1998;341:309-315.

18. Haller JA, Bandello F, Belfort R Jr, et al; Ozurdex GENEVA Study Group. Dexamethasone intravitreal implant in patients with macular edema related to branch or central retinal vein occlusion twelve-month study results. Ophthalmology. 2011;118(12):2453-2460.

19. Pe'er J, Folberg R, Itin A, Gnessin H, Hemo I, Keshet E. Vascular endothelial growth factor upregulation in human central retinal vein occlusion. Ophthalmology. 1998;105:412-416.

20. Noma H, Funatsu H, Mimura T, Harino S, Hori S. Vitreous levels of interleukin- 6 and vascular endothelial growth factor in macular edema with central retinal vein occlusion. Ophthalmology. 2009;116:87-93.

21. Noma H, Funatsu H, Yamasaki M, et al. Aqueous humour levels of cytokines are correlated to vitreous levels and severity of macular oedema in branch retinal vein occlusion. Eye (Lond). 2008;22: 42-48.

22. Ehlers JP, Fekrat S. Retinal vein occlusion: beyond the acute event. Surv Ophthalmol. 2011;56:281-299.

23. Ehlers JP, Fekrat S. Differential effects of triamcinolone and bevacizumab in central retinal vein occlusion. Can J Ophthalmol. 2011;46: 88-89.

24. Ehlken C, Rennel ES, Michels D, et al. Levels of VEGF but not $\operatorname{VEGF}(165 \mathrm{~b})$ are increased in the vitreous of patients with retinal vein occlusion. Am J Ophthalmol. 2011;152:298.e1-303.e1.

25. Aiello LP, Avery RL, Arrigg PG, et al. Vascular endothelial growth factor in ocular fluid of patients with diabetic retinopathy and other retinal disorders. $N$ Engl J Med. 1994;331:1480-1487.

26. Hahn P, Fekrat S. Best practices for treatment of retinal vein occlusion. Curr Opin Ophthalmol. 2012;23:175-181.

27. Brown DM, Campochiaro PA, Bhisitkul RB, et al. Sustained benefits from ranibizumab for macular edema following branch retinal vein occlusion: 12-month outcomes of a phase III study. Ophthalmology. 2011;118: $1594-1602$.

28. Sophie R, Hafiz G, Scott AW, et al. Long-term outcomes in ranibizumabtreated patients with retinal vein occlusion; the role of progression of retinal nonperfusion. Am J Ophthalmol. 2013;156:693-705.

Clinical Ophthalmology

\section{Publish your work in this journal}

Clinical Ophthalmology is an international, peer-reviewed journal covering all subspecialties within ophthalmology. Key topics include: Optometry; Visual science; Pharmacology and drug therapy in eye diseases; Basic Sciences; Primary and Secondary eye care; Patient Safety and Quality of Care Improvements. This journal is indexed on Submit your manuscript here: http://www.dovepress.com/clinical-ophthalmology-journal
29. Heier JS, Campochiaro PA, Yau L, et al. Ranibizumab for macular edema due to retinal vein occlusions: long-term follow-up in the HORIZON trial. Ophthalmology. 2012;119:802-809.

30. Campochiaro PA, Sophie R, Pearlman J, et al; RETAIN Study Group. Long-term outcomes in patients with retinal vein occlusion treated with ranibizumab: the RETAIN study. Ophthalmology. 2014;121:209-219.

31. Campochiaro PA, Wykoff CC, Singer M, et al. Monthly versus asneeded ranibizumab injections in patients with retinal vein occlusion: the SHORE study. Ophthalmology. 2014;121:2432-2442.

32. Rush RB, Simunovic MP, Aragon AV 2nd, Ysasaga JE. Treat-andextend intravitreal bevacizumab for branch retinal vein occlusion. Ophthalmic Surg Lasers Imaging Retina. 2014;45:212-216.

33. Narayanan R, Panchal B, Das T, et al; MARVEL Study Group. A randomised, double-masked, controlled study of the efficacy and safety of intravitreal bevacizumab versus ranibizumab in the treatment of macular oedema due to branch retinal vein occlusion: MARVEL Report No. 1. Br J Ophthalmol. 2015;99(7):954-959.

34. Martin DF, Maguire MG, Ying GS, et al; CATT Research Group. Ranibizumab and bevacizumab for neovascular age-related macular degeneration. N Engl J Med. 2011;364:1897-1908.

35. Diabetic Retinopathy Clinical Research Network, Wells JA, Glassman AR, et al. Aflibercept, bevacizumab, or ranibizumab for diabetic macular edema. N Engl J Med. 2015;372:1193-1203.

36. Wroblewski JJ, Wells JA 3rd, Gonzales CR. Pegaptanib sodium for macular edema secondary to branch retinal vein occlusion. Am J Ophthalmol. 2010;149:147-154.

37. Regnier SA, Larsen M, Bezlyak V, Allen F. Comparative efficacy and safety of approved treatments for macular oedema secondary to branch retinal vein occlusion: a network meta-analysis. BMJ Open. 2015;5: e007527.

38. Bakri SJ. Clinical trials: a need to better define the control group as current standard of care. Ophthalmology. 2015;122:443-444.

39. Hahn P, Fekrat S. Aflibercept for central retinal vein occlusion: an ongoing revolution or are we spinning in place? Am J Ophthalmol. 2013; 155:415.e2-417.e2.

40. Stone TW. ASRS preferences and trends membership survey. American Society of Retina Specialists (ASRS). 2015. Available from: https:// www.asrs.org/content/documents/_2015-pat-survey-results.pdf. Accessed August 20, 2015.

41. Grunwald JE, Pistilli M, Ying GS, et al; Comparison of Age-related Macular Degeneration Treatments Trials Research Group. Growth of geographic atrophy in the comparison of age-related macular degeneration treatments trials. Ophthalmology. 2015;122:809-816.

42. Tan MH, McAllister IL, Gillies ME, et al. Randomized controlled trial of intravitreal ranibizumab versus standard grid laser for macular edema following branch retinal vein occlusion. Am J Ophthalmol. 2014; 157:237.e-247.e.

43. Campochiaro PA, Hafiz G, Mir TA, et al. Scatter photocoagulation does not reduce macular edema or treatment burden in patients with retinal vein occlusion: the RELATE Trial. Ophthalmology. 2015; 122:1426-1437.

PubMed Central and CAS, and is the official journal of The Society of Clinical Ophthalmology (SCO). The manuscript management system is completely online and includes a very quick and fair peer-review system, which is all easy to use. Visit http://www.dovepress.com/ testimonials.php to read real quotes from published authors. 